\title{
Employing the quality function deployment (QFD) method to support knowledge management in innovation process planning
}

\author{
Przemysław Polak, Warsaw School of Economics, Poland, ppolak@sgh.waw.pl \\ Magdalena Jurczyk-Bunkowska, The Opole University of Technology, Poland, m.jurczyk- \\ bunkowska@po.opole.pl
}

\begin{abstract}
This article proposes the use of Quality Function Deployment (QFD) matrix diagram to one of the stages of the innovation process planning. The purpose of this approach is to support knowledge management, specifically the codification of tacit knowledge. Innovation processes are usually carried out by multidisciplinary teams in which arrangements are often problematic due to communication problems. An example of the choice of an innovative solution in a manufacturing company shows the extent to which the use of the QFD method diagram helps to share knowledge in order to take decisions related to planning the goal of the innovation process. We proposed the modification of QFD matrix to include the scale of risk characterizing each of analyzed solutions.
\end{abstract}

Keywords: Innovation management, planning, quality function deployment, knowledge management

\section{Introduction}

Innovations are key factors in competitiveness increase (Vives, 2008). They provide better quality and new products, more efficient organization, cost control, or other solutions that the market demands. However, in the literature it appears that there are many interpretations of the concept of innovation. An unquestionable feature of the innovation is novelty. Thus, the innovation is the application of new knowledge in a company so that it can stimulate the growth and respond to environmental or situational requirements. There is not equivocal assessment of the knowledge novelty degree. Therefore, Rogers's (2003) proposal should be accepted in which it is said that the innovation is an idea, practice, or object that is perceived as new by an individual or other unit of adoption.

The essence of innovation management is to ensure the long-term competitive advantage of the organization (Pleschak \& Sabisch, 1996). The contemporary market proves that assets allow the creation of competitive success of a company are organizational knowledge and the knowledge of employees (Benbya, 2008). Knowledge in an organization is defined as a flexible mix of framed experiences, values, contextual information, as well as expert insight that provides a framework for evaluating and incorporating new experiences and information. Knowledge originates and is applied in the minds of the workers. In organizations, knowledge often becomes embedded not only in documents or repositories, but also in organizational routines, processes, practices and norms (Davenport \& Prusak, 1998). Therefore, knowledge management is to ensure the acquisition, creation, as well as sharing of both explicit and tacit knowledge in an organization, so 
that it achieves better results of its activities (Massingham \& Massingham, 2014). Knowledge management improves the organizational ability of a company and affects better utilization of its resources, both material and intangible assets. Therefore, it should be a part of everyday business processes and activities, as well as sharing knowledge among employees must be promoted (Desouza \& Paquette, 2011). In the context of knowledge management, some of the most challenging processes are innovation processes, which are focused on creating new knowledge for the development of commercial solutions (Herkema, 2003).

Sharing created knowledge is the foundation of successfully implemented innovation processes. This applies primarily to the tacit knowledge, which includes the experience, skills, insights, and visions of employees and managers. Interactions between people allow the creation of new combinations of knowledge, and thus yielding innovation. In this sense, the ability of an enterprise to increase in tacit knowledge and to create preconditions for sharing among employees, within an organizational unit and among organizational units, is the main task of a knowledge management system (Adams \& Lamont, 2003). Unfortunately, it is a very difficult challenge, particularly with regard to employees from different functional departments. They usually have different background and a different point of reference in the evaluation of the enterprise. This paper proposes the use of a modified matrix from the Quality Function Deployment (QFD) method as a tool to support the arrangements for the implementation plan of innovation. The proposed solution solves the problem of the knowledge exchange between the company managers from different departments. In the case discussed later in this article, each of decision makers understood the necessity of the company development through the implementation of innovation. However, they had different opinions about the scope and form of a solution in which they were to invest their time and resources. The use of the QFD matrix as a tool to support the exchange of knowledge could lead to a joint agreement. Participation in the decision-making process created an opportunity for the authors to conduct a research based on a case study.

The purpose of this research was to verify the use of the QFD method to share knowledge in order to take decisions related to planning the goals of innovation processes. We propose modification of the QFD matrix including the scale of risk characterizing each of the analyzed solutions. This article presents a case study of a manufacturing company, which applied the proposed method to choosing the variant of an innovative solution for implementation. This article discusses issues related to knowledge management in the planning of innovation processes, especially the problems of uncertainty, sharing tacit knowledge, and providing equal levels of knowledge. We identified those characteristics of the QFD method, which support knowledge management in various areas. Necessary modifications to the standard QFD matrix were discussed, allowing its use in relation to innovations. Furthermore, the direct and indirect effects of the use of such approach were analyzed and discussed. In the summary, we point to the opportunities offered by the use of QFD method in support of innovation process planning.

\section{Knowledge Management in Innovation Processes}

An innovation process can be defined in the context of knowledge as a knowledge process aimed at creating new knowledge geared towards the development of commercial and viable solutions. Innovation is a process wherein knowledge is acquired, shared, and assimilated with the aim of creating new knowledge, which embodies products and services (Herkema, 2003). Therefore, 
knowledge management is the key to the efficient and effective implementation of the innovation processes. Knowledge management includes two aspects, 'managing' the knowledge that already exists in an organization, as well as enhancing the ability to create 'new knowledge' (Albers \& Brewer, 2003). Traditionally, knowledge is defined as information put into a certain context. Nonaka, Toyama, and Konno (2000) noted that knowledge creation is necessarily contextdependent in terms of who participates and how they participate. They introduced the concept of 'ba' as a space for knowledge creation in organizations. Ba can be considered as a shared space for emerging relationships. According to Nonaka et al. (2000), this space can be either physical (e.g. office, dispersed business space, etc.), virtual (e.g. e-mail, teleconference, etc.), mental (e.g. shared experiences, ideas, ideals, etc.), or any combination of these. The most important roles that knowledge management plays in improving innovation capability of an enterprise are (Krstić \& Petrović, 2012):

- codifying and sharing tacit knowledge

- acquiring and sharing explicit knowledge

- enabling cooperation within and outside the enterprise

- integrating knowledge

- providing availability of knowledge

- creating organizational culture based on knowledge and innovation

The essence of innovation processes is the creation and implementation of new knowledge. Therefore, they have very strong relationship with knowledge management. Knowledge is not only a collection of data stored in computer databases and information retrieved from such sources. It is also composed of the tacit values, emotions, and intuitions (Nonaka \& Takeuchi, 1995). In fact, those elusive elements control innovation processes implemented in enterprises. And although for all stakeholders the most important goal is to increase in competitiveness, they see different ways to achieve this. Therefore, from the very beginning of the innovation process, its key element is learning which is the exchange of knowledge between stakeholders. New technologies play a vital role in this process, supporting the sharing and distribution of knowledge among employees. However, IT-supported forms of formal communication are not sufficient in case of innovation processes, which are poorly structured, extremely dynamic, and often chaotic due to the high level of risk and uncertainty. In this respect, the function of knowledge management is to reduce uncertainty of the final outcome of an innovation process (Tidd, 2009).

The second main characteristic feature of the innovation processes is their multidisciplinary nature. It is connected with the involvement in innovation processes of people with different skills and professional interests, who see specific information in different contexts. The transfer of knowledge is ineffective, and the agreement difficult to reach, if the parties give different meanings to the same information. This problem becomes even more complex, if they do not use the same terminology, and assign different meanings to the same term. This justifies the need for the development of specialized tools for innovation process management, which support acquiring, processing, codifying, transferring, and the application of knowledge. Eventually, such system can lead to leveling knowledge between the members of a team involved in the innovation process. Such actions are reasonable with respect to every stage of the innovation process planning. However, they appear to be the most desirable in relation to the determination of the purpose of innovation, because it defines the direction for tasks and decisions performed within the whole 
process. The determination of the innovation process purposed here is based on the transformation of input information, which is often in the form of tacit knowledge. The information must be analyzed in a common context in order to reach an agreement. This means that the collection of information and the creation of an appropriate context for the analysis require using appropriate methods and tools.

\section{The Usage of the Quality Function Deployment (QFD)}

QFD can be defined as a method of planning and development of a product or a service that enables research teams to make precise specification of customer needs and requirements, then to translate them into the parameters of the product or service, its components, as well as parameters of the production process (Christiano, Liker, \& White, 2000). The earliest known implementation of QFD took place in the Kobe Shipyards of Mitsubishi Heavy Industry in 1966 (Akao, 1997). Then, it was utilized by the Toyota plants and since that time, QFD usage has expanded rapidly to various industries (Shahin, 2008). However, the term "Quality Function Deployment" was not employed at that time. It was first used in 1972 but not popularized until 1980s (Akao, 1997). Along with the popularization of QFD, a number of modifications and extensions have been developed. They are related not only to the enrichment of research proceedings, but also they are associated with the application of the method in new domains (Shahin, 2008). The areas of QFD implementation include, among others:

- $\quad$ strategy development in education (Lee, Lo, Leung, \& Ko, 2000)

- enhancing quality in education (Park, Kim, Kwak, \& Lee, 2013)

- strategy formulation in the banking industry (Ko \& Lee, 2000)

- improving service quality in the hotel industry (Kuo, Chen, \& Boger, 2015)

- quick response to changing customer needs within the bank sector (Andronikidis, Georgiou Gotzamani, \& Kamvysi, 2009)

- quality evaluation of train's internal services (Khorshidi, Nikfalazar, \& Gunawan, 2016)

- improving the service quality of casual-dining restaurants (Cheng, Tsai, \& Lin, 2015)

- global facility location-allocation problem (Jamalnia, Mahdiraji, Sadeghi, Hajiagha, \& Feili, 2014)

- $\quad$ software development (Jayaswal, Patton, 2006)

The original version of QFD is used for product development, enabling project teams to make detailed specifications of the needs and expectations of customers by referring them to the technical solutions and possibilities for their introduction. The essence of the QFD method is that the value of product technical parameters depends on customers' requirements described in their natural language. Thus, it is a tool enabling the translation of information from the market to the technical features of the product, and furthermore, it becomes a platform for the exchange of knowledge between technical designers and those responsible for customer service.

A common platform for the exchange of knowledge from different sources is also the basis of arrangements defining the objectives of innovation processes. Therefore, we decided to support this step by using QFD tool called House of Quality. Its specific name is associated with the shape of a diagram, which in its upper part, resembles the roof of a house. Due to the nature of innovation processes, the diagram was modified by adding fields related to the risk of the implementation of 
an innovation, as the derivative of a knowledge gap which in the innovation process must be compensated by an enterprise (See Figure 1).

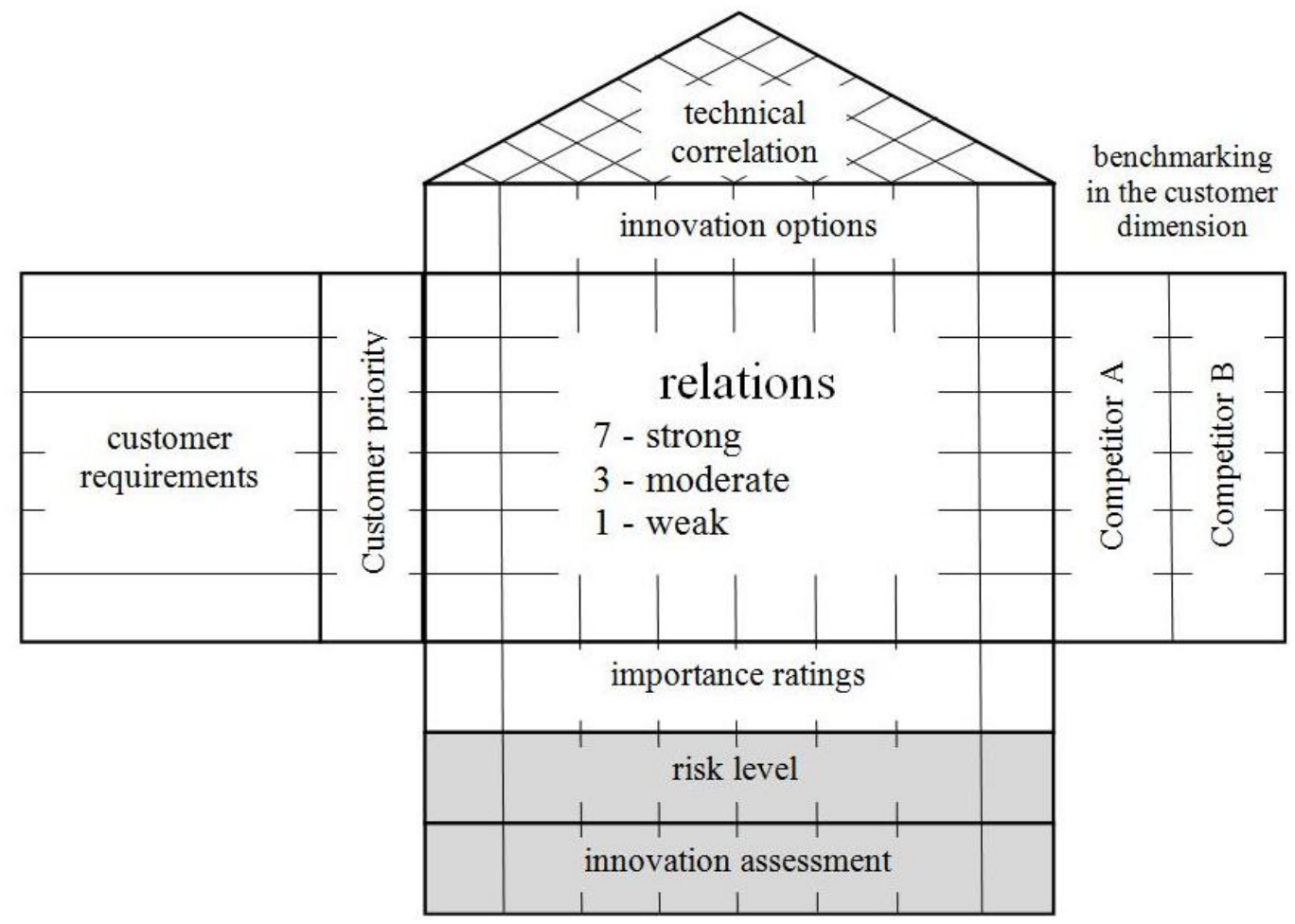

Figure 1. The QFD matrix modified for innovation planning

The risk and the uncertainty of innovation processes depend on two factors (Jurczyk-Bunkowska, 2013):

- novelty

- the scope of changes implemented in the organization

Both factors affect the size of the knowledge gap, which during the course of innovation process, should be narrowed. If the knowledge gap is smaller, there is a greater chance of success in the implementation of a new solution. A large knowledge gap is associated with high risk of failure due to the inability to produce, acquire, or implement the missing knowledge. The supply of knowledge on new technologies is limited, hence the cost of acquiring it is high. Furthermore, solutions characterized by a high degree of novelty require accumulating new knowledge through conducting experiments. Solutions that are imitations and require the implementation of new knowledge, which is already to some extent rooted in the company environment, are much less risky, but are associated with a less durable competitive advantage. Also, the scope of changes caused by the implementation of innovations has crucial influence on the size of the knowledge gap, and thus on the degree of risk. The wider changes, the more employees have to acquire new knowledge. The level of the risk is also affected by changes in procedures between the functional departments of a company.

The final evaluation of innovation variants (field: innovation assessment; See Figure 1) in the modified QFD matrix takes into account the following aspects: 
1. The impact of innovation on criteria important from the point of view of a customer (field: relations)

2. Technical linkages between particular variants of innovation (field: technical correlations)

3. The reference to competitors (competitor $\mathrm{A}$ - the leader in the segment, competitor $\mathrm{B}$ - the nearest competitor) in terms of criteria relevant to a customer

4. The level of risk resulting from the size of a knowledge gap characterizing each innovation variant (field: risk level)

\section{Research Methodology}

The reorganization of an enterprise based on innovation implementation is a very complex issue. Its analysis requires a holistic approach and in-depth analysis of interrelated activities. It is influenced by operational conditions and the experience and motivation of management. Such analyses are not possible based solely on quantitative methods. Therefore, we used a case study as a tool in order to formulate conclusions regarding the causes and effects of using the QFD method to consider the development strategies of the production system.

An opportunity to conduct the research was provided by the participation in a project 'Knowledge Transfer to SME Through Training and Consulting' funded by the European Social Fund. The task of the working group was the analysis of production processes in a company and the indication of the possibility of their reorganization. The participation in the project provided researchers with an insight into the production processes and the decision problems faced by the management staff. In those conditions, we could not only make observations and generate hypothesis, but also were able to test the proposed solution as well. Thus, due to the organizational limitation and our participation in the decision making process, the research was limited to a single case. However, Flyvbjerg (2006) claimed that a single case study can provide reliable information about the broader class, especially if it provides the chances for the analysis of deeper causes behind a given problem and its consequences.

The results of the case study may be used as a framework for the practical use of the proposed solution by other companies. However, due to the complexity and multifaceted nature of the problem of innovation process planning, similar case studies carried out under different conditions can produce completely different results.

\section{An Example of Using the QFD Method in Planning Innovation Processes}

The case presented in this article demonstrates the problem of choosing one of the alternative solutions, perceived in the organization as innovations. It is a case of a small enterprise engaged in the production of furniture to a customer's order. Its production process includes the design, manufacture and final assembly of furniture at a customer location. Three years before carrying out the research described in this article, the company owners decided to significantly increase manufacturing capacity by moving to the newly built production hall equipped with high-end machinery. The incurred huge investment gave the expected effect of the change in the business profile and the entrance to the much more profitable markets. The new standard of service allowed for the significant expansion of sales. New production workers and assemblers were hired. The enterprise started cooperation with local companies aiming at different target markets. Currently, 
produced of customized furniture can be classified as premium, due to the potential of design, manufacturing, and quality. At present, the company carries out projects in Poland and other countries. It participated in the 'EuroCucina 2016' trade fair in Milan, where they presented their arrangements attracting new European customers.

Despite the joint management of the family business, the tasks were clearly divided. One of the co-owners was engaged in the design of construction and technology. The second was responsible for planning orders and supplies, and the third supervised production. They were assisted by four office workers performing tasks related to marketing and finance.

Encouraged by the success, the company saw opportunities for further expansion through continuous development. The managers analyzed the implementation of new solutions in the production system. At some point, it was necessary to take a decision involving the selection of one of six possible to implement proposals:

1. The purchase and implementation of a computer system enabling to create the visualization of furniture prototypes in a virtual environment.

2. The development of an expert system, based on artificial intelligence, supporting pricing of orders, taking into account the workload, including manufacturing by hand and the use of alternative furniture accessories.

3. The reorganization of procurement by giving up many suppliers and focusing on one specific assortment group. That would involve the implementation of the B2B system automating the procurement process.

4. The reorganization of the production control process and the implementation of management by the project, in which a team leader would be responsible for the execution of orders from the measurement in a customer apartment, through the preparation and the approval of the interior design project, to the installation of the finished product.

5. The implementation of the Enterprise Resource Planning (ERP) system.

6. Establishing cooperation with an external company entirely dedicated to furniture and interior design, to consequently outsourcing this phase of the production process.

All those proposals perceived by the organization as the application of new knowledge. However, each proposal leads to different effects. It is difficult to compare them without proper analysis. Implementing all those solutions at the same time would be organizationally and economically irrational or fiscally not feasible. Despite numerous discussions, the managers could not find a common context for making comparisons and choosing one of the options. It should also be noted that the owners realized that each variant was characterized by different novelty degree and financial risks. Reaching consensus on priorities in case of such decision entails the possibility of serious conflicts. Under such conditions, the use of the modified QFD matrix is reasonable. It allows to exchange knowledge between different functional departments of the company, determine the basis of the plan, and, to be precise, to determine the purpose of work on the enhancement of the production system through the implementation of an innovation. The most important issue, from the point of view of the entire system and all of company managers, is to improve competitiveness. The main point of reference in the decision-making process was meeting customers' requirements, which determined the growth of competitiveness. In the discussed case, the main criteria of competitiveness included:

- $\quad$ attractive, i.e. functional, visually striking and original design 
- on-time order completion

- price competitiveness, based on the correctly identified cost of a project

- the possibility of customer participation in furniture design

- short turnaround time

Figure 2 shows the QFD matrix for the analyzed case. In the area of determining the importance of customer requirements the opinions of the company managers have been used. The same approach has been employed in order to fill the field of relations between customer requirements and innovative solutions possible to implement in the production system. The modification of QFD matrix includes defining the scale of risk characterizing each of the analyzed solutions. The risk is higher when the knowledge gap (which must be filled in order to implement a specific innovation in the company) is bigger. To determine the degree of risk associated with a particular variant of the innovation, expert judgment, or inference based on fuzzy logic can be used (JurczykBunkowska, 2013). The second approach is more accurate, but is not suitable for the use in case of decision-making in a small company because it is too labor-intensive and mathematically advanced. Therefore, a 1-5 scale has been used, and on that basis, the risk associated with different variants of innovation has been quantified.

All variants of innovation in the analyzed example can be classified as an imitation. Nevertheless, the development of the expert system supporting order pricing is much more innovative than the implementation of the ERP system and changing the procurement process by implementing the $\mathrm{B} 2 \mathrm{~B}$ system. In case of the development of the pricing system based on rules, the knowledge must be produced inside the company or on its behalf in an external organization (e.g. a university). However, such a solution carries more risk of a potential failure than the innovation of an imitation type. In addition, it entails higher financial expenditures and the need for greater involvement of management in its implementation. All these factors must be considered when evaluating solutions. But in case of the implementation of ERP and B2B systems, necessary knowledge can be acquired from outside the company at the relatively lower cost. For this reason, these two solutions characterize lower risk, although they cover more business processes in the company. These considerations show why it is so important to take into account the risks in the comprehensive assessment of innovations. 


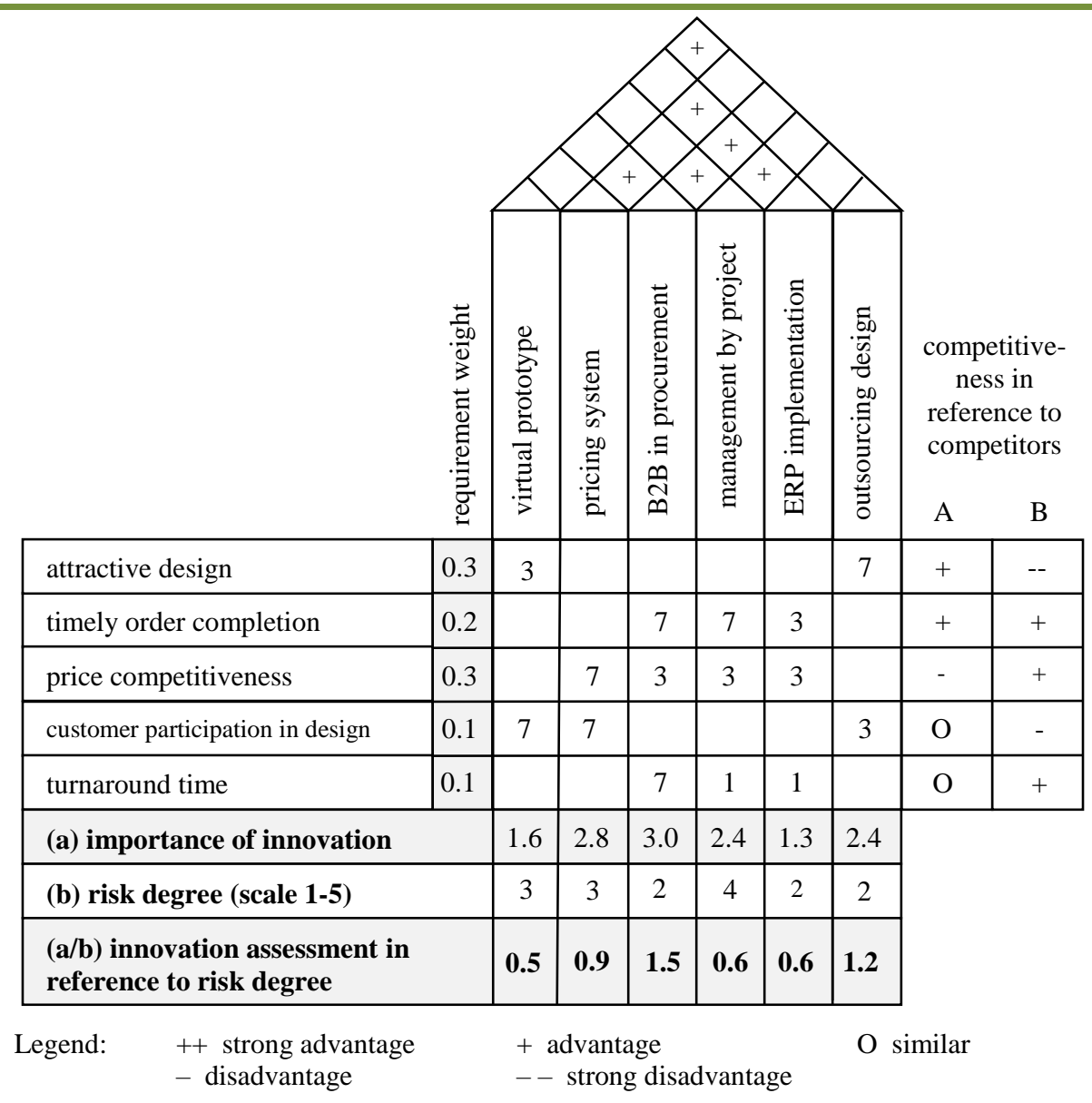

Figure 2. QFD method diagram applied for the evaluation of innovative solutions in the production system

The analysis of QFD matrix shown in Figure 2 confirms that the implementation of the B2B solution in the procurement has the greatest importance in relation to the company strategy. It should strongly affect the timely delivery of orders, as the current cooperation with many suppliers of the same materials actually does not minimize costs. This affects negatively the timely delivery of materials, which has consequences in the timely execution of orders by the company. The owners also face the problem of errors in orders and incomplete deliveries. The implementation of this solution should also shorten the order execution time, because placing and monitoring deliveries and financial settlements is a very time consuming activity. The selected variant may also enhance in future the introduction of other solutions such as the ERP implementation, and management by project. What's more, this solution is characterized by a low degree of risk, and therefore, it has been finally recommended to the managers. However, the most important outcome of the QFD matrix application is not the selection of solution, but the arrangements based on the common view of the possible impact of each solution on the company. 


\section{The Outcomes of Supporting Knowledge Management in the Planning of Innovation Processes Through the Use of the QFD Method Diagram}

The essence of knowledge management is filling knowledge gaps construed as the difference between the available knowledge resources and the knowledge necessary for completing a decision-making process. In practice, there is a big gap between available knowledge and ability to apply that knowledge (Pfeffer \& Sutton, 2000). This gap, in case of innovation process planning, can be filed by the use of the QFD method.

The proposed approach supports communication processes during which part of knowledge is lost. If there are more intermediate levels between the sender and the recipient, the loss of knowledge is greater. The proposed approach fits into a dynamic capabilities theory originating from a resource-based theory. It assumes that organizations constantly integrate, reconfigure, renew and recreate their resources and capabilities, and most importantly, upgrade and reconstruct their core capabilities in response to the changing environment to attain and sustain competitive advantage (Wang \& Ahmed, 2007). This requires organizational capacity to create and absorb new knowledge (Zollo \& Winter, 2002). What it means is the ability to transform individual knowledge into knowledge embedded in an organization through specific mechanisms. Literature in the field of Knowledge-Based View (KBV) perceives knowledge as the most important strategic asset and the basis for the innovation potential in both large (Chen, Jiao, \& Zhao, 2016) and small enterprises (Hutchinson \& Quintas, 2008). This theory emphasizes the relationship between knowledge and competitiveness. The ability of an enterprise to integrate and use acquired knowledge is the driving force of innovation, which determines the competitive advantage of a company (Matusik \& Hill, 1998). It is especially the knowledge used to enhance processes that leads to the improvement in company indicators (Richey, Genchev, \& Daugherty, 2005). From this point of view, the main factor that allows a company to achieve success is to know what the company does, how it is done, and why it happens (Zack, 2003).

Organizations tend to use knowledge in explicit form that is easy to store and transmit through the language (Rantapuska \& Ihanainen, 2008). However, in order to be successful, it is necessary to integrate the explicit knowledge with the hidden knowledge to create new opportunities (Cohen \& Levinthal, 1990). This can be achieved by, proposed in this paper, the use of QFD matrix, which integrates the knowledge of individuals inside the organization. The proposed solution also supports the learning processes of the organization by collecting, selecting, and distributing information. The collection and codification of information also support creating unique combinations because mental processes also create new knowledge leading to better performed activities, and in this case, the innovation processes.

The joint analysis of the purpose of an innovation process leads to the exchange of experiences and allows to verify the available resources of knowledge by eliminating outdated or useless knowledge. It may also be an element of strategy development by reaching consensus about a new perspective on the functioning of a company.

The application of the QFD leads to the combination of knowledge from different areas. The formal record of the findings and arrangements is essential for an effective multistage group analysis. The proposed solution enabled the practical application of knowledge treated as a 
resource of the whole organization. Previous attempts to agree on changes to the production system had been time-consuming and had not led to the formulation of proposals in an unambiguous manner. The use of the QFD method diagram enabled to transform tacit knowledge into explicit knowledge, formal and possible to write in words and numbers. That made it available for future analysis and multiple use. Therefore, it may be part of the construction of an information system supporting the implementation of innovation processes.

\section{Conclusions}

The quality of management processes is determined by the access to information and knowledge, and by the level of arrangements for implementing solutions resulting from the business strategy. The case study presented in this article shows how the QFD method was used to reach agreement on the managerial level. The strength of the QFD method, namely a matrix called the House of Quality, is its popularity and common acceptance. This allows using the method without tedious training for identifying and explaining relations between certain technical solutions. In this case, they were innovative solutions affecting different functional areas of the company. A key element was referencing the effects of changes to customer requirements, which determine the competitiveness of the company.

The ambiguity of the evaluation results is the crucial problem of the innovation implementation and new knowledge application in a company. When starting a new innovation process, it is possible to assume certain changes in the value of indicators (e.g. production cost, sales volume, etc.). At this stage, however, the details of the solutions are not yet known, so the final effects of the innovation implementation may differ significantly from those initially planned. Thus, many managers are currently making decisions based on intuition and predictions, and not on specific values. This is very uncomfortable, because they prefer to be able to make decisions based on a solid analysis. The approach proposed in this paper reduces the problem associated with that challenge by providing a quantitative method of evaluation to provide additional knowledge for the decision. The estimation of the impact of individual solutions on customer requirements provides numerical values that are much easier to compare with each other than verbal descriptions. Due to such an assessment, it is also possible to consider more carefully the variants and the justification of the final decision.

The case study of the small company presented in this article demonstrates that the most important result achieved by the implementation of the modified QFD matrix is the system perspective on the development needs of the company. This leads to making decisions, which not only improve a single fragment of the enterprise, but also involve a holistic effect correlated with the company strategy. In the course of further investigation, it should be verified whether a similar advantage could be obtained also for larger organizations. The disadvantage of the proposed approach is the subjectivity of ratings given by individual decision makers. For example, small organizations lack the ability to systemically assess the risk. However, the joint discussions leading to common findings show that the use of the proposed approach may provide a convenient platform for communication and the exchange of knowledge between people dealing every day with different areas of the company. Even in small businesses, where person-to-person relationships are stronger, it is necessary to stimulate the exchange of views from the perspective of the goals of an entire organization rather than individual functional areas. The knowledge shared by a group of people 
has a much higher value than the knowledge of a single person, because it leads to synergy. Therefore, it must be emphasized that the advantage of this solution is motivating the transfer of knowledge and achieving consensus. The workload of preparing the QFD matrix does not play a significant role considering that such decisions are rarely made. It is more difficult for small enterprises where competence in the use of formal management tools is lower. In conclusion, the use of the QFD method diagram can be effective for increasing the efficiency of collaborative decision-making, which, in the discussed case above, was planning the innovation process, and providing the platform for the exchange of tacit knowledge.

\section{References}

Adams, G. L., \& Lamont, B. T. (2003). Knowledge management systems and developing sustainable competitive advantage. Journal of Knowledge Management, 7(2), 142-154.

Akao, Y. (1997). QFD: Past, present, and future. International Symposium on QFD, 97(2), 1-12.

Albers, J. A., \& Brewer, S. (2003). Knowledge management and the innovation process: The ecoinnovation model. Journal of Knowledge Management Practice, 4.

Andronikidis, A., Georgiou, A. C., Gotzamani, K., \& Kamvysi, K. (2009). The application of quality function deployment in service quality management. The TQM Journal, 21(4), 319333.

Benbya, H. (2008). Knowledge management system implementation: Lessons learnt from Silicon Valley. Oxford: Chandos Publishing.

Chen, J., Jiao, H., \& Zhao, X. (2016). A knowledge-based theory of the firm: managing innovation in biotechnology. Chinese Management Studies, 10(1), 41-58.

Cheng, C. C., Tsai, M. C., \& Lin, S. P. (2015). Developing strategies for improving the service quality of casual-dining restaurants: New insights from integrating IPGA and QFD analysis. Total Quality Management \& Business Excellence, 26, 415-429.

Christiano J. J., Liker J. K., \& White C. C. (2000). Customer driven product development through Quality Function Deployment in the USA and Japan. Journal of Product Innovation Management, 17, 286-308.

Cohen, W., \& Levinthal, D. (1990). Absorptive capacity: A new perspective on learning and innovation. Administrative Science Quarterly, 35(1), 128-152.

Davenport, T., \& Prusak, L. (1998). Working knowledge: How organizations manage what they know. Boston: Harvard Business School Press.

Desouza, K. C., \& Paquette, S. (2011). Knowledge management: An introduction. London: Facet Publishing.

Flyvbjerg, B. (2006). Five misunderstandings about case-study research. Qualitative inquiry, 12(2), 219-245.

Galbraith, J. (1977). Organization design. Reading: Addison Wesley.

Herkema, S. (2003). A complex adaptive perspective on learning within innovation projects. The Learning Organization, 10(6), 340-346. 
Hutchinson, V., \& Quintas, P. (2008). Do SMEs do knowledge management? Or simply manage what they know? International Small Business Journal, 26(2), 131-154.

Jamalnia, A., Mahdiraji, H. A., Sadeghi, M. R., Hajiagha, S. H. R., \& Feili, A. (2014). An integrated fuzzy QFD and fuzzy goal programming approach for global facility locationallocation problem. International Journal of Information Technology \& Decision Making, 13, 263-290.

Jayaswal, B. K., \& Patton, P. C. (2006). Design for trustworthy software: Tools, techniques, and methodology of developing robust software. Upper Saddle River: Pearson Education.

Jurczyk-Bunkowska, M. (2013). Characteristics of decision problems in innovation process planning. Proceedings of the 14th European Conference on Knowledge Management, Reading, UK: Academic Conferences and Publishing International Limited, 795-804.

Khorshidi, H. A., Nikfalazar, S., \& Gunawan, I. (2016). Statistical process control application on service quality using SERVQUAL and QFD with a case study in trains' services. The TQM Journal, 28(2), 195-215.

Ko, A. S. O., \& Lee, S. F. (2000). Implementing the strategic formulation framework for the banking industry of Hong Kong. Managerial Auditing Journal, 15, 469-477.

Krstić, B., \& Petrović, B. (2012). The role of knowledge management in increasing enterprise's innovativeness. Facta Universitatis. Economics and Organization, 9(1), 93-110.

Kuo, C. M., Chen, H. T., \& Boger, E. (2015). Implementing city hotel service quality enhancements: Integration of Kano and QFD analytical models. Journal of Hospitality Marketing \& Management, 25(6), 748-770.

Lee, S. F., Lo, K. K., Leung, R. F., \& Ko, A. S. O. (2000). Strategy formulation framework for vocational education: Integrating SWOT analysis, balanced scorecard, QFD methodology and MBNQA education criteria. Managerial Auditing Journal, 15(8), 407-423

Massingham, P. R., \& Massingham, R. K. (2014). Does knowledge management produce practical outcomes? Journal of Knowledge Management, 18, 221-254.

Matusik, S., \& Hill, C. (1998). The utilization of contingent work, knowledge, and competitive advantage. Academy of Management Review, 23(4), 680-697.

Nonaka, I., \& Takeuchi, H. (1995). The knowledge creating company: How Japanese companies create the dynamics of innovation, New York: Oxford University Press.

Nonaka, I., Toyama, R., \& Konno, N. (2000). SECI, Ba and leadership: A unified model of dynamic knowledge creation. Long Range Planning, International Journal of Strategic Management, 33(1), 5-34.

Park, B. T., Kim, B. K., Kwak, M. S., \& Lee, E. S. (2013). Extraction of CTQ for the improvement of the education quality using QFD in college. Journal of the Korea Safety Management and Science, 15, 231-239.

Pfeffer, J., \& Sutton, R. (2000). The knowing-doing gap. How smart companies turn knowledge into action. Boston, MA: Harvard Business School Press.

Pleschak F., \& Sabisch H. (1996). Innovations management. Stuttgart: Schäfferoeschel Verlag. 
Rantapuska, T., \& Ihanainen, O. (2008). Knowledge use in ICT investment decision making of SMEs. Journal of Enterprise Information Management, 21(6), 585-596.

Richey, R. G., Genchev, S. E., \& Daugherty, P. J. (2005). The role of resource commitment and innovation in reverse logistics performance. International Journal of Physical Distribution \& Logistics Management, 35(4), 233-257.

Rogers, E. M. (2003). Diffusion of innovations. New York: Free Press.

Shahin, A. (2008). Quality function deployment (QFD): A comprehensive review. In: T. P. Rajmanohar, Total Quality Management. Contemporary Perspectives and Cases (47-79). Andhra Pradesh: ICFAI University Press.

Tidd, J., \& Bessant, J. (2009). Managing innovation: Integrating technological, market and organizational change. Chichester: John Wiley \& Sons.

Vives, X. (2008). Innovation and competitive pressure. The Journal of Industrial Economics, $56(3), 419-469$.

Wang, C. L., \& Ahmed, P. K. (2007). Dynamic capabilities: A review and research agenda. The International Journal of Management Reviews, 9(1), 31-51.

Zack, M. (2003). Rethinking the knowledge-based organization. Sloan Management Review, 44(4), 67-71.

Zollo, M., \& Winter, (2002). Deliberate learning and the evolution of dynamic capabilities. Organization Science, 13(3), 339-351.

\section{Authors' Biographies}

Przemyslaw Polak is a senior lecturer and a director of the Postgraduate Studies in Business Analysis in the Institute of Information Systems and Digital Economy at the Warsaw School of Economics. He is also an independent consultant in the field of information systems.

Magdalena Jurczyk-Bunkowska is an assistant professor in the Faculty of Production Engineering and Logistics at the Opole University of Technology. Her research interests include operational management as well as the innovation process management. 